\title{
CORRIGENDUM
}

\section{The role of vertebral augmentation in multiple myeloma: International Myeloma Working Group Consensus Statement}

MA Hussein, FD Vrionis, R Allison, J Berenson, S Berven, E Erdem, S Giralt, S Jagannath, RA Kyle, S LeGrand, R Pflugmacher, N Raje, SV Rajkumar, RL Randall, D Roodman, D Siegel, R Vescio, J Zonder and BGM Durie on behalf of the International Myeloma Working Group

Leukemia (2008) 22, 1649; doi:10.1038/leu.2008.181

Correction to: Leukemia advance online publication, 29 May 2008; doi:10.1038/leu.2008.127

Since the publication of the above paper, the authors have noticed an error in Dr Randall's name.
The correct name is shown above.

The authors apologize for any inconvenience caused. 